EDITORIAL

\title{
Logros y avances del Instituto de Investigaciones en Ciencias de la Salud de la Universidad Nacional de Asunción, Paraguay. Año 2014
}

El Instituto de Investigaciones en Ciencias de la Salud dependiente del Rectorado de la Universidad Nacional de Asunción es una de las Instituciones líderes en el área de Investigación, Servicio Especializado y Formación de Investigadores a través de su Programa de Maestría en el área de la Salud.

En el 2014, dos grupos de investigadores del IICS tuvieron importante logros en el área de la Ciencias de la Salud. El primero de ellos se obtuvo como resultado del trabajo titulado "Distribución de aislados de variantes de $\mathrm{VPH}-16$ en mujeres paraguayas con diferentes grados de lesión cervical". Por esta investigación, el Congreso Nacional Paraguayo otorgó el Premio Nacional de Ciencia 2014 al grupo de investigadores del IICS.

El trabajo galardonado fue un estudio multidisciplinario que se inició en el 2007 con profesionales de distintas áreas, recibiendo además colaboración de científicos de Argentina y Uruguay. Entre los hallazgos más importantes se encuentra la detección de una alta frecuencia del virus del papiloma humano (VPH) de alto riesgo oncogénico en mujeres sin lesión de cuello uterino, en su mayoría a partir de los 30 años, lo cual es relevante debido a que a esta edad la mujer tiene más riesgo de poseer una infección persistente que con el paso del tiempo le produzca una lesión del cuello uterino. Las cifras alarmantes de mujeres infectadas por el VPH, que el trabajo pone de manifiesto, se obtuvieron mediante el uso de un método de detección altamente sensible y específico. De esta manera, se puede tener un panorama claro de la enfermedad en el Paraguay.

El segundo logro fue a través del estudio titulado "Innovación diagnóstica aplicada a casos de infecciones respiratorias agudas graves en niños" y al que se adjudicó una Mención de honor del Premio Nacional de Ciencia 2014. Este trabajo multicéntrico, iniciado en el 2.010, permitió la detección cuali-cuantitativa de múltiples agentes microbiológicos en pacientes hospitalizados con infecciones respiratorias agudas graves.

Los resultados de estas investigaciones servirán de base a los decisores a nivel de salud pública para el diseño e implementación de estrategias preventivas y terapéuticas, y priorizar así los esfuerzos de diagnóstico.

Todos estos logros se obtuvieron gracias al compromiso, no sólo de los investigadores, sino también de las autoridades del IICS, pues si bien es cierto que para hacer investigación lo más importante son las ganas y la capacitación en aspectos metodológicos, la sostenibilidad del proceso necesita del soporte económico y logístico de las Instituciones.

Los resúmenes de los trabajos ganadores se presentan en la sección "Otros" de este número.

Otros avances y logros obtenidos por el IICS se refieren a la adjudicación de financiación de 23 proyectos de investigación en el marco del "Componente I: Fomento a la Investigación Científica del Programa Paraguayo para el Desarrollo de la Ciencia y Tecnología - PROCIENCIA-Convocatoria 2013". 
Los proyectos adjudicados se enmarcan dentro de las siguientes líneas de investigación del IICS.

1. Factores de virulencia de virus y bacterias

2. Enfermedades transmitidas por vectores

3. Desarrollo e implementación de herramientas diagnósticas

4. Innovaciones tecnológicas en salud

5. Patologías genéticas

6. Patógenos emergentes

7. Medio ambiente y salud

8. Enfermedades autoinmunes

9. Prevención del cáncer del cuello uterino y HPV

La lista de los proyectos adjudicados se presenta en la sección "Otros" de este número. Adicionalmente, el programa de Maestría en Ciencias Biomédicas del IICS fue adjudicado para recibir apoyo financiero en el marco del "Programa de Apoyo para la Formación de Docentes - Investigadores".

Además, los recursos adquiridos dentro de estos proyectos permitirán la formación de jóvenes investigadores, en las líneas de investigación antes mencionadas, quienes tendrán la opción de iniciarse en el marco del Programa de Maestría en Ciencias Biomédicas que la Institución ofrece.

Todo lo mencionado no hace más que estimular a los investigadores de esta institución para así seguir aportando al desarrollo del país y porque no mejorar la calidad de vida de nuestra población.

Prof. Dr. Nelson Apuril Cespedes, Director General Instituto de Investigaciones en Ciencias de la Salud, UNA 